\title{
Subannular repair for moderate to severe ischemic mitral regurgitation: Still a long way to go. Authors' reply
}

\author{
Baotong Li, Hansong Sun \\ State Key Laboratory of Cardiovascular Disease, Department of Adult Cardiac Surgery, \\ Fuwai Hospital, National Center for Cardiovascular Disease, \\ Chinese Academy of Medical Science, Peking Union Medical College, Beijing, China
}

I thank the author for the letter "Moderate to severe ischemic mitral regurgitation: More data to guide the choice. Why not consider the use of subvalvular repair?" [1]. As presented in the original article "Long-term outcomes of mitral valve annuloplasty versus subvalvular sparing replacement for severe ischemic mitral regurgitation" [2], ring annuloplasty (RA) was performed without subvalvular repair, which was in according with the practice guidelines [3]. In addition, it was found that compared with the mitral valve replacement group, the incidence of mitral regurgitation recurrence was significantly higher in the RA group $(\mathrm{p}<0.001)$ [3].

Ischemic mitral regurgitation (MR) is frequently associated with myocardial infarction. With the dilatation of the ventricle, the papillary muscles are displaced, and the leaflets are pulled downward and laterally. In the most frequent inferior infarction, this leaflet tethering is observed in the area of the posteromedial commissure. What is more, the annulus dilates secondarily to both the dilatation of the ventricle and the MR, which enters a vicious cycle $[3,4,5]$. According to practice guidelines, mitral valve (MV) repair with an undersized complete rigid annuloplasty ring may be considered in patient with severe ischemic MR who remain symptomatic despite guideline directed medical and cardiac device therapy and who do not have a basal aneurysm/dyskinesis, significant leaflet tethering, or severe left ventricular enlargement (COR IIb, LOE B) [3]. Though there are different kinds of techniques for MV repair, such as annu- loplasty and subannular repair [4, 6-9], guidelines do not specifically point out which of the currently available valve repair approaches are superior. In accordance with practice guidelines, the technique of RA was easy-to-accomplish, effective and safe, it is also common at the documented center, these results are shown in a retrospective study [2].

According to the Alain Carpentier functional classification, MR of type I is characterized by annular dilation, while type IIIb is characterized by restricted motion of the leaflets because of tethering $[8,10]$. As documented in the results of recent studies, both of type I and type IIIb are common for ischemic MR, and ischemic MR is a secondary pathology where the underlying mechanism is not eradicated by either subannular repair or RA alone $[4,5]$.

Undersized RA. Undersized RA is designed to correct MR of type I. Although it is perhaps less technically challenging and associated with lower shortterm complication rates, the high rate of recurrent MR after repair attenuates the potential benefit of RA. Several studies have suggested that posterior leaflet tethering after undersized RA is the main underlying mechanism associated with MR recurrence $[7,10]$. Capoulade et al. [10] concluded that left ventricular ring mismatch was associated with significant recurrent MR in patients after undersized RA.

Subannular repair. Because misalignment of the papillary muscles appears to be the main problem, techniques directed at papillary muscle realignment have been suggested, and two techniques are available in the literature.

Address for correspondence: Hansong Sun, MD, PhD, State Key Laboratory of Cardiovascular Disease, Department of Adult Cardiac Surgery, Fuwai Hospital, National Center for Cardiovascular Disease, Chinese Academy of Medical Science, Peking Union Medical College, Beijing, China, tel: +86 010 88322351, fax: +86 01088322351 , e-mail: drsunhs@sina.com 
1. Pausch et al. [8] proposed a modified subannular maneuver to correct type IIIb MR while combining undersized RA with a controlled realignment of both papillary muscles, thereby fixing the distance between mitral annular plane and papillary muscle tips. Double-armed pledgeted 3-0 Polytetrafluorethylene sutures were passed through the trunks of both papillary muscles in a U-formed fashion, and then both suture ends were subsequently passed through the posterior mitral valve annulus and the annuloplasty ring (i.e., in the P1 segment for anterolateral papillary muscle and in the P3 segment for posteromedial papillary muscle) from the ventricular to atrial side. Though they concluded that this technique was feasible and reproducible, having a clear potential to significantly decrease MR recurrence and improve 1-year outcome compared to isolated annuloplasty, one should be aware of the risk of papillary muscle injuries.

2. With the technique of papillary muscle approximation, Nappi et al. [9] carried a randomized study aimed at elucidating the effective benefit of papillary muscle surgery in long-term follow-up. Finally, compared with under sizing RA only, papillary muscle approximation with under sizing RA exerted a long-term beneficial effect on left ventricular remodeling, which improved long-term cardiac outcome, but did not produce differences in overall mortality or quality of life. Though the benefits of papillary muscle approximation seemed to be remarkable, the percentage of moderate-to-severe MR recurrence was still as high as $27 \%$. Of note, in the condition of severely adverse left ventricular remodeling, both of the papillary muscles might be displaced significantly. As a result, the technique of papillary muscle approximation could not relieve leaflet tethering effectively.

As no consensus regarding the most appropriate surgical strategy for subannular repair is available so far, more studies should be carried out. In addition, it should be verified whether the technique of papillary muscle approximation with $\mathrm{RA}$ is superior to mitral valve replacement.

Conflict of interest: None declared

\section{References}

1. Nenna A, Chello M, Nappi F. Moderate to severe ischemic mitral regurgitation: More data to guide the choice. Why not consider the use of subvalvular repair? Cardiol J. 2020; 27(2): 220-222, doi: 10.5603/CJ.2020.0051.

2. Li B, Wu H, Sun H, et al. Long-term outcomes of mitral valve annuloplasty versus subvalvular sparing replacement for severe ischemic mitral regurgitation. Cardiol J. 2019; 26(3): 265-274, doi: 10.5603/CJ.a2018.0006, indexed in Pubmed: 29570209.

3. Kron IL, LaPar DJ, Acker MA, et al. American Association For Thoracic Surgery Ischemic Mitral Regurgitation Consensus Guidelines Writing Committee. 2016 update to The American Association for Thoracic Surgery consensus guidelines: Ischemic mitral valve regurgitation. J Thorac Cardiovasc Surg. 2017; 153(5): 1076-1079, doi: 10.1016/j.jtcvs.2016.11.068, indexed in Pubmed: 28190606.

4. Nishimura RA, Otto CM, Bonow RO, et al. 2014 AHA/ACC guideline for the management of patients with valvular heart disease: a report of the American College of Cardiology/American Heart Association Task Force on Practice Guidelines. J Thorac Cardiovasc Surg. 2014; 148: e1-e132.

5. Kron IL, Acker MA, Adams DH, et al. American Association for Thoracic Surgery Ischemic Mitral Regurgitation Consensus Guidelines Writing Committee. 2015 The American Association for Thoracic Surgery Consensus Guidelines: Ischemic mitral valve regurgitation. J Thorac Cardiovasc Surg. 2016; 151(4): 940-956, doi: 10.1016/j.jtcvs.2015.08.127, indexed in Pubmed: 26995621.

6. Fino C, Iacovoni A, Ferrero $\mathrm{P}$, et al. Restrictive mitral valve annuloplasty versus mitral valve replacement for functional ischemic mitral regurgitation: an exercise echocardiographic study. J Thorac Cardiovasc Surg. 2014; 148(2): 447-53.e2, doi: 10.1016/j.jtcvs.2013.05.053, indexed in Pubmed: 24199762.

7. Nishimura RA, Otto CM, Bonow RO, et al. 2017 AHA/ACC Focused Update of the 2014 AHA/ACC Guideline for the Management of Patients With Valvular Heart Disease: A Report of the American College of Cardiology/American Heart Association Task Force on Clinical Practice Guidelines. J Am Coll Cardiol. 2017; 70: 252-289.

8. Pausch J, Harmel E, Sinning C, et al. Standardized subannular repair for type IIIb functional mitral regurgitation in a minimally invasive mitral valve surgery setting $\dagger$. Eur J Cardiothorac Surg. 2019; 56(5): 968-975, doi: 10.1093/ejcts/ezz114, indexed in Pubmed: 31005995 .

9. Nappi F, Spadaccio C, Nenna A, et al. Papillary muscle approximation versus restrictive annuloplasty alone for severe ischemic mitral regurgitation. J Am Coll Cardiol. 2016; 67(20): 2334-2346, doi: 10.1016/j.jacc.2016.03.478, indexed in Pubmed: 27199056.

10. Capoulade R, Zeng X, Overbey JR, et al. Cardiothoracic Surgical Trials Network (CTSN) Investigators. Impact of left ventricular to mitral valve ring mismatch on recurrent ischemic mitral regurgitation after ring annuloplasty. Circulation. 2016; 134(17): 1247-1256, doi: 10.1161/CIRCULATIONAHA.115.021014, indexed in Pubmed: 27777294. 